\title{
Evaluasi Stabilitas Sifat Fisika Kimia Sediaan Krim Ketoconazole dengan Metode Stabilitas Penyimpanan Jangka Panjang
}

\author{
Sudrajat Sugiharta ${ }^{1 *}$, Widia Ningsih ${ }^{2}$ \\ ${ }^{1}$ Prodi Farmasi, FF UBP Karawang, Karawang, Jawa Barat, Indonesia \\ 2Prodi Farmasi, Politeknik Meta Industri Cikarang, Cikarang, Jawa Barat, Indonesia \\ *E-mail : penapharmacy@gmail.com \\ (Submit 19/12/2021, Revisi 20/12/2021, Diterima 30/12/2021, Terbit 31/12/2021)
}

\begin{abstract}
Abstrak
Latar belakang: Mutu sediaan obat penting dipertahankan selama proses pembuatan, penyimpanan hingga digunakan. Stabilitas sediaan krim merupakan salah satu kriteria yang penting dari mutu sediaan tersebut karena akan berdampak pada efektifitas, keamanan dan mutu produk pada saat digunakan oleh masyarakat. Penelitian ini bertujuan untuk menguji stabilitas sifat fisika sediaan krim ketoconazole dengan metode stabilitas penyimpanan jangka panjang (real time). Metode: Penelitian menggunakan praeksperimental dengan rancangan one shot case study dengan pengujian stabilitas jangka panjang sediaan krim ketoconazole selama 42 bulan dengan

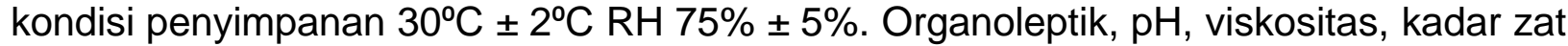
aktif ketoconazole diperiksa dengan interval waktu penyimpanan selama $24,30,36$, dan 42 bulan. Hasil dan Diskusi: Penelitian menunjukkan bahwa efek penyimpanan selama 42 bulan pada pengujian organoleptik tidak menyebabkan perubahan bau, warna, dan tekstur, dimana tidak terbentuk lapisan krim serta masih mempertahankan kehomogenan. Pada pengujian $\mathrm{pH}$, dan viskositas dari krim ketoconazole tidak berubah secara signifikan $(p \geq 0.05$ ) setelah 42 bulan penyimpanan pada kondisi penyimpanan $30^{\circ} \mathrm{C} \pm 2^{\circ} \mathrm{C} \mathrm{RH} 75 \% \pm 5 \%$. Pada penetapan kadar zat aktif ketoconazole dalam krim selama penyimpanan tidak menunjukan degradasi yang signifikan (terjadi penurunan kadar kurang dari 5\% pada penetapan kadar). Kesimpulan: Data yang diperoleh dari uji stabilitas jangka panjang menunjukan bahwa sediaan krim ketoconazole tetap stabil selama 42 bulan penyimpanan.
\end{abstract}

Kata kunci: Krim Ketoconazole, Kadar aktif, Organoleptik, pH, Stabilitas jangka panjang

\section{Pendahuluan}

Sediaan obat penting mempertahankan sifat dan karakteristiknya agar tetap sama selama proses pembuatan, penyimpanan hingga digunakan. Stabilitas sediaan krim 
menjadi salah satu kriteria yang penting dari mutu sediaan tersebut karena akan berdampak pada efektifitas, keamanan dan mutu produk pada saat digunakan oleh masyarakat. Ketoconazole berbentuk krim beredar luas di masyarakat dimana bentuk ini terpilih karena menyenangkan dalam penggunaan, mudah menyebar rata, dan juga praktis digunakan $^{(1)}$.

Sediaan krim merupakan bentuk terpilih karena menyenangkan dalam penggunaan, mudah menyebar rata, dan praktis digunakan. Kemampuan krim ketoconazole dalam mempertahankan sifat dan karakteristiknya menjadi permasalahan tersendiri dimana harus memenuhi persyaratan meliputi kestabilan, homogenitas, kemudahan dipakai, dan harus terdispersi merata pada saat penggunaannya ${ }^{(1)}$, maka dari itu penting diketahui stabilitas dari krim itu sendiri selama penyimpanan. Menurut Pramudita(2) stabilitas merupakan kemampuan suatu produk obat untuk bertahan dalam batas spesifikasi yang diterapkan sepanjang periode penyimpanan dan penggunaan untuk menjamin identitas, kekuatan, kualitas, dan kemurnian produk. Sediaan krim dikatakan stabil jika sifat dan karakterisasinya masih berada dalam batas yang dapat diterima selama masa periode penyimpanan dan penggunaan sama dengan yang dimilikinya pada saat dibuat( ${ }^{(3)}$.

Penyimpanan krim dalam waktu yang lama akan mengakibatkan kerusakan krim atau stabilitas krim berkurang (4). Menurut CPOB (5) uji stabilitas dilakukan guna menilai karateristik stabilitas obat dan untuk menentukan kondisi penyimpan yang sesuai dengan tanggal kadarluwarsa. Dalam uji stabilitas mempertimbangkan iklim, dimana Indonesia termasuk kedalam Zona IV (benua Asia), pengujian stabilitas obat yang umum yaitu uji stabilitas jangka panjang (realtime) dan uji dipercepat ${ }^{(6)}$. Untuk produk krim dalam pengujian stabilitas jangka panjang biasanya pengujian dilakukan pada suhu kamar yang dikendalikan yaitu $30^{\circ} \mathrm{C}$, kelembaban ruangan $75 \% \pm 5 \%$ dengan rentang waktu pengujian pada bulan $0,3,9,12,18,36,48$, dan 60 . Biasanya pengujian dilakukan sampai bulan ke-36, tetapi apabila masih memenuhi syarat pengujian harus terus diteruskan sampai bulan ke-60 (7).

Parameter yang digunakan dalam uji kestabilan fisika krim yaitu organoleptik yang bertujuan untuk mengamati perubahan warna atau bau, pemeriksaan $\mathrm{pH}$, krim sebaiknya memiliki $\mathrm{pH}$ yang sesuai dengan $\mathrm{pH}$ kulit, jika $\mathrm{pH}$ terlalu asam akan mengakibatan kulit menjadi iritasi. Selain itu pengujian kestabilan fisika yang lain yaitu viskositas, daya sebar, homogenitas, dan pengujian kadar zat aktif (8).

Kami menemukan beberapa penelitian uji stabilitas krim, pada pengujian sediaan krim selama penyimpanan 28 hari menunjukan krim tidak mengalami perubahan bau, warna, pertumbuhan jamur, dan tidak terbentuk lapisan pada permukaan krim $^{(9)}$. Sementara dalam pengujian stabilitas krim dalam penyimpanan selama 8 minggu pada suhu rendah $\left(4^{\circ} \mathrm{C}\right)$, suhu kamar, dan suhu tinggi $\left(40 \pm 2^{\circ} \mathrm{C}\right)$, setiap dua minggu sekali menunjukkan organoleptik, pengukuran $\mathrm{pH}$, dan pengukuran diameter globul tidak terpengaruhi selama penyimpanan ${ }^{(10)}$. Pengujian yang lebih lanjut telah dilakukan oleh Rismana et $a^{(11)}$, pengamatan stabilitas fisika krim antiacne melalui uji organoleptik 
sampai minggu ke 24 pada suhu kamar menunjukan tidak ada perubahan signifikan dari bentuk, warna, bau dan homogenitas, namun pada penyimpanan suhu $40^{\circ} \mathrm{C}$ selama 12 minggu menunjukan perubahan yang tidak signifikan pada warna dan bau. Dalam pengujian stabilitas dikaji kadar zat aktif yang dikandungnya, dalam penentuan kadar ketoconazole dapat digunakan metode spektrofotometri. di dasarkan pada reaksi oksidasi atau kompleksasinya dengan ion logam ${ }^{(12)}$.

Kami menemukan pengujian stabilitas sediaan ketoconazole pada penyimpanan selama 6 bulan, 15 bulan penyimpanan, namun saat ini masih jarang penelitian yang

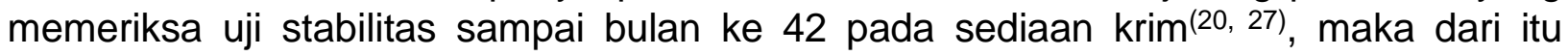
menjadi dasar pemilihan pengujian stabilitas jangka panjang untuk memastikan kualitas sediaan krim ketoconazole. Penelitian ini bertujuan untuk mengetahui pengaruh kondisi penyimpanan jangka panjang terhadap hasil evaluasi fisika kimia sediaan krim ketoconazole dengan parameter organoleptik, $\mathrm{pH}$, viskositas, dan kadar zat aktif selama 42 bulan penyimpanan.

\section{Metode}

\section{Alat}

pH meter (Mettler Toledo), Viskometer Brookfield Cone and plate set AT 71 362, Gelas kimia (Pyrex), Erlenmeyer (Pyrex), Spatel, Gelas ukur (Pyrex), Labu ukur (Pyrex), Kertas perkamen, Pipet tetes, Sonicate (Elmasonic P), Spektofotometer (Spectrophotometer UV-VIS 2600), Timbangan analitik ( Mettler Toledo).

\section{Bahan}

Krim ketoconazole (Sediaan komersial yang diperoleh dari PT. XXX), ketoconazole standar, metilen klorida, air bebas $\mathrm{CO}_{2}$.

\section{Prosedur Rinci}

\section{Sampling}

Sampel pada penelitian ini adalah krim ketoconazole yang diambil dari sampel pertinggal. Teknik pengambilan sampel ini menggunakan metode Fraihat dan Bahgat (2014) yang dimodifikasi(12). Sampel pertinggal yang didapatkan sekurang-kurangnya diambil dari 1 bets dalam 1 tahun, pengambilan menggunakan teknik random sampling dimana sampel diambil setelah proses pengemasan tube yaitu pada posisi awal, bagian tengah, dan bagian akhir .

\section{Uji Stabilitas}

Pengujian stabilitas jangka panjang digunakan untuk menilai stabilitas krim ketoconazole secara fisika dan kimia setelah penyimpanan selama 42 bulan. Sampel 
disimpan dalam kemasan terakhirnya selama pengujian dengan kondisi penyimpanan $30^{\circ} \mathrm{C} \pm 2^{\circ} \mathrm{C} \mathrm{RH} 75 \% \pm 5 \%$ dan terhindar dari cahaya matahari langsung(6). Organoleptik, $\mathrm{pH}$, viskositas, kadar zat aktif ketoconazole diperiksa dengan interval waktu penyimpanan selama $24,30,36$, dan 42 bulan.

\section{Uji Organoleptik}

Pengujian organoleptis dilakukan dengan cara pengamatan secara visual sediaan krim ketoconazole setelah penyimpanan, dilakukan penilaian dari bentuk fisik sediaan yaitu perubahan warna, bentuk dan bau krim serta homogenitas. Pengujian homogenitas krim dilakukan dengan mengoleskan krim pada kaca objek, kemudian dikatupkan dengan kaca objek yang lainnya untuk diamati homogenitasnya, apabila tidak terdapat butiran-butiran kasar di atas kaca objek tersebut maka krim yang diuji homogen ${ }^{(1)}$.

\section{Uji pH}

Pengukuran $\mathrm{pH}$ dari sampel menggunakan $\mathrm{pH}$ meter (Mettler Toledo). $\mathrm{pH}$ meter dikalibrasi terlebih dahulu sebelum digunakan. Dalam penetapan $\mathrm{pH}$ sampel menggunakan vial berwarna coklat tipe II - treated soda lime glass (gelas soda kapur yang diproses), karena sifat zat aktif yang tidak tahan terhadap cahaya, maka diperlukan wadah tersebut agar dalam penetapan $\mathrm{pH}$ nilai yang diperoleh itu akurat. Elektroda dimasukan ke dalam sampel dan dibaca nilai $\mathrm{pH}$ yang muncul. Sebanyak $1 \mathrm{~g}$ sampel dilarutkan dalam air dengan volume $10 \mathrm{ml}$ air bebas $\mathrm{CO} 2, \mathrm{pH}$ yang terbaca dicatat kemudian dibandingkan perubahan $\mathrm{pH}$ setelah interval penyimpanan pengujian stabilitas ${ }^{(23)}$.

\section{Uji Viskositas}

Uji viskositas sampel menggunakan metode Erwiyani et al. (2017) dengan modifikasi(23) dilakukan dengan alat Viskometer Brookfield Cone and plate set AT 71362 pada suhu $25 \pm 0.3^{\circ} \mathrm{C}$. Spindle CPE 41 dicelupkan ke dalam krim kemudian hasil yang tertera di layar dicatat setelah menunjukan angka yang stabil, angka tersebut merupakan viskositas krim dengan satuan $\mathrm{cP}=1 \mathrm{mPa} \cdot \mathrm{s}$. Uji viskositas sampel dilakukan dengan interval waktu selama pengujian stabilitas jangka panjang Prosedur ini apakah prosedur baru/modifikasi? Jika tidak, maka setiap prosedur wajib melampirkan sitasi/sumber

\section{Uji Kadar Ketoconazole}

\section{Prosedur pembacaan}

Penelitian ini menyajikan studi tentang pengujian kadar krim ketoconazol dengan menggunakan metode Fraihat dan Bahgat (2014) yang dimodifikasi(12). Spektrofotometer yang digunakan yaitu UV-VIS. Scan spektrum dari masing-masing larutan standar dan sampel pada panjang gelombang antara 200-340 nm dengan menggunakan metilen klorida sebagai blanko pengenol. 
Direkam dan dibandingkan spektrum kedua larutan. Panjang gelombang maksimum yang diperoleh dari peak larutan sampel harus sama atau sesuai dengan panjang gelombang maksimum peak larutan standar.

\section{Prosedur penetapan kadar ketoconazole}

Cahaya yang melewati sampel ketoconazole di deteksi menggunakan spektrofotometer UV-VIS dengan panjang gelombang \pm 295 , digunakan pelarutan metilen klorida untuk melarutkan ketoconazole standar dan sampel.

\section{Prosedur preparasi}

Untuk larutan standar timbang $50 \mathrm{mg}$ ketoconazole standar, masukan ke dalam labu ukur $50 \mathrm{ml}$, encerkan dengan metilen klorida hingga tanda batas volume, kemudian kocok hingga larut. Pipet $4 \mathrm{ml}$ larutan, encerkan dengan metilen klorida hingga tanda batas $25 \mathrm{ml}$, kemudian kocok homogen. Untuk larutan sampel timbang $1 \mathrm{~g}$ sampel krim, masukan ke dalam labu ukur $50 \mathrm{ml}$, larutkan dengan metilen klorida hingga tanda batas volume, lalu di sonikasi selama 15 menit. Pipet $4 \mathrm{ml}$ larutan, encerkan dengan metilen klorida hingga tanda batas $25 \mathrm{ml}$, kemudian kocok hingga homogen.

\section{Prosedur pembacaan dan perhitungan kadar}

Dibaca absorbansi masing-masing larutan standar dan sampel pada panjang gelombang $295 \mathrm{~nm}$ menggunakan metilen klorida sebagai blanko pengenol.

Dihitung kadar sampel dengan persamaan berikut: kadar: $[\mathbf{A u} / \mathbf{A s}] \mathbf{x} \mathbf{C}$

Dimana:

Au: Absorbansi larutan sampel

As: Absorbansi larutan standar

C: Kadar standar seperti yang tercantum pada tabel (\%)

Tabel 1. Analisa zat aktif

\begin{tabular}{|l|l|l|}
\hline Sampel & $\begin{array}{l}\text { Kadar } \\
\text { ketoconazole }\end{array}$ & Spesifikasi \\
\cline { 1 - 2 } Sampel 1A & & \multirow{2}{*}{$90-110 \%$} \\
\cline { 1 - 2 } Sampel 1B & & \\
\hline Rata-rata & &
\end{tabular}

Penentuan spesifikasi untuk penetapan kadar, organoleptik, viskositas, $\mathrm{pH}$, mengacu pada referensi kompendial 


\section{Analisis Statistik}

Analisis statistik digunakan one-way ANOVA $(\alpha=0,05)$ untuk menganalisis hasil pengamatan stabilitas fisika meliputi viskositas, $\mathrm{pH}$, dan kadar ketoconazole selama waktu penyimpanan. Jika hasil analisis statistik didapatkan nilai $p<0,05$ maka terdapat perbedaan bermakna selama waktu penyimpanan dan sediaan dikatakan tidak stabil selama waktu penyimpanan. Untuk uji organoleptis diamati sebagai data deskriptif.

\section{Hasil}

\section{Uji organoleptik}

Pengamatan organoleptik pada uji stabilitas fisika sediaan krim ketoconazole yang telah di analisa memberikan hasil sebagai berikut:

Tabel 2. Hasil Pemeriksaan Organoleptik

\begin{tabular}{|c|c|c|c|c|}
\hline \multirow[t]{2}{*}{ Parameter } & \multicolumn{4}{|c|}{$\begin{array}{c}\text { Bulan penyimpanan dengan suhu } \\
30^{\circ} \mathrm{C} \pm 2^{\circ} \mathrm{C} \text { RH } 75 \%=5 \%\end{array}$} \\
\hline & 24 & 30 & 36 & 42 \\
\hline Warna & Putih & Putih & Putih & Putih \\
\hline Bau & Lemah & Lemah & Lemah & Lemah \\
\hline
\end{tabular}

Dari data pada tabel 2. menunjukan bahwa pengujian stabilitas fisika sediaan krim ketoconazole dilakukan terhadap parameter organoleptik yang meliputi warna dan bau pada suhu penyimpanan $30^{\circ} \mathrm{C}$. Pada bulan ke $24,30,36$, hingga ke 42 masih mempertahankan konsistensinya yaitu berwarna putih dan bau lemah.

Pada pengujian homogenitas krim ketoconazole bertujuan untuk melihat seluruh komponen krim telah tercampur dengan baik atau tidak. Hasil uji homogenitas dari krim dapat dilihat pada tabel berikut.

Tabel 3. Uji homogenitas krim

\begin{tabular}{cl}
\hline Bulan Penyimpanan & $\begin{array}{c}\text { Homogenitas } \\
(\mathrm{n}=3)\end{array}$ \\
\hline 24 & Homogen \\
30 & Homogen \\
36 & Homogen \\
42 & Homogen \\
\hline
\end{tabular}




\section{Penetapan pH}

Penetapan $\mathrm{pH}$ pada sediaan krim ketoconazol dilakukan secara potensiometri yaitu menggunakan elektroda. Penetapan $\mathrm{pH}$ sediaan ini menggunakan $\mathrm{pH}$ meter yang sudah terstandarisasi, berfungsi dengan baik dan sudah terkalibrasi. Elektroda dibilas terlebih dahulu dengan air purified water yang sudah di saring, lalu dibilas sedikit oleh sampel yang akan di uji. Eletroda dikeringkan terlebih dahulu sebelum di masukan ke dalam sampel. Berikut ini hasil penetapan $\mathrm{pH}$ yang telah dianalisa yaitu:

Tabel 4. Hasil Pemeriksaan $\mathrm{pH}$

\begin{tabular}{|c|c|}
\hline $\begin{array}{c}\text { Bulan } \\
\text { Penyimpanan }\end{array}$ & $\begin{array}{c}\mathrm{pH} \\
(\mathrm{n}=3)\end{array}$ \\
\hline 24 & $4,3 \pm 0,02$ \\
\hline 30 & $4,2 \pm 0,03$ \\
\hline 36 & $4,2 \pm 0,08$ \\
\hline 42 & $4,2 \pm 0,05$ \\
\hline
\end{tabular}

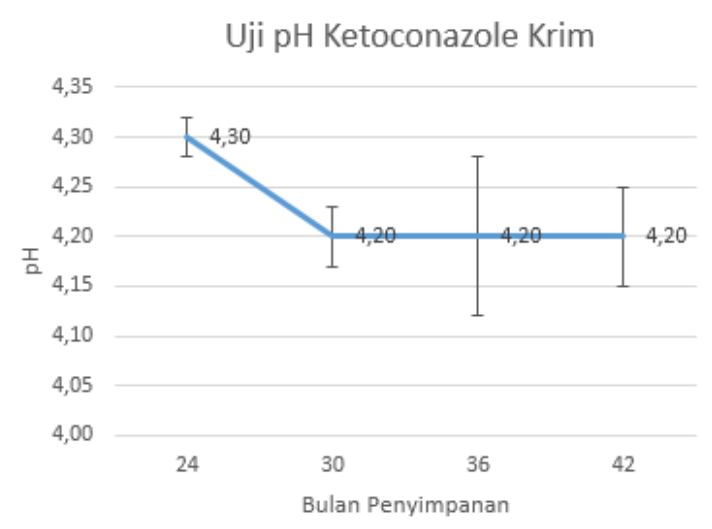

Gambar 1. Uji pH Ketoconazole Krim

Dari tabel 4 dan gambar 1 menunjukan hasil pengujian $\mathrm{pH}$ sediaan krim ketoconazole selama proses penyimpanan pada suhu $30^{\circ} \mathrm{C}$, pada bulan ke $24 \mathrm{pH}$ yang didapatkan yaitu $4,3 \pm 0,02$, lalu terjadi penurunan pada bulan ke 30 yaitu $4,2 \pm 0,03$ sedangkan $\mathrm{pH}$ tetap sama pada bulan ke 36 yaitu 4,2 $\pm 0,08$ dan bulan ke 42 yaitu 4,2 $\pm 0,05$.

\section{Uji Viskositas}

Pengamatan viskositas sediaan ketoconazole krim dilakukan menggunakan alat Viskometer Brookfield Cone and plate set AT 71362 pada suhu $25 \pm 0.3{ }^{\circ} \mathrm{C}$ dengan menggunakan Spindle CPE 41. Berikut ini adalah hasil uji viskositas dari krim ketoconazole. 
Tabel 5. Uji viskositas krim ketoconazole

\begin{tabular}{cc}
\hline $\begin{array}{c}\text { Bulan } \\
\text { Penyimpanan }\end{array}$ & Viskositas \pm SD $(\mathrm{cP})$ \\
$(\mathrm{n}=3)$ \\
\hline 24 & $48782,30 \pm 202,02$ \\
30 & $48750,75 \pm 117,10$ \\
36 & $48690,52 \pm 107,05$ \\
42 & $48685,68 \pm 302,54$ \\
\hline
\end{tabular}

\section{Uji Viskositas Ketoconazole Krim}

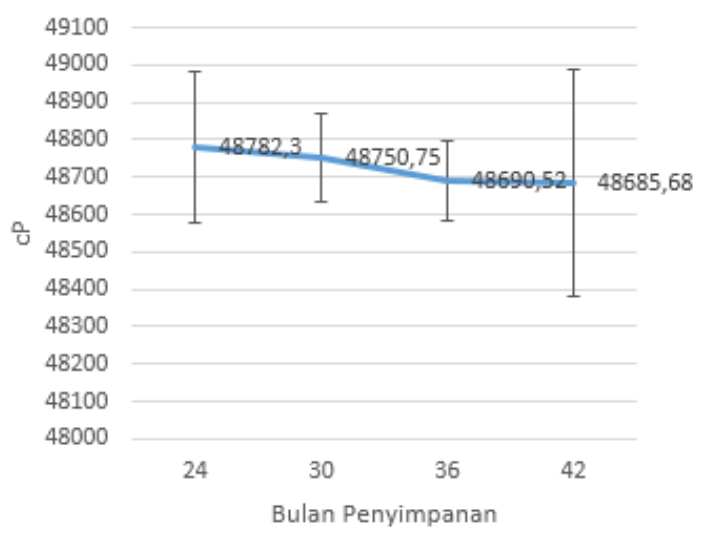

Gambar 2. Uji viskositas ketoconazole krim

Hasil uji viskositas sediaan ketoconazole krim dilakukan pada kecepatan $5 \mathrm{rpm}$. Berdasarkan tabel 5 dan gambar 2 tersebut menunjukkan terjadinya penurunan viskositas krim selama interval waktu penyimpanan.

\section{Penetapan Kadar}

\section{Penentuan kurva kalibrasi}

Kurva kalibrasi merupakan metode yang digunakan untuk menentukan kadar ketoconazole dalam sampel menggunakan deret seri larutan standar yang telah diketahui konsentrasinya. Konsentrasi larutan standar yang membentuk deret seri ditetapkan untuk menentukan kisaran linear yang menyatakan hubungan antara konsentrasi zat dalam larutan standar dengan respon serapan dari spektrofotometer UV-VIS. Hasil penetapan linear dinyatakan dengan koefisien korelasi $(r)$ yang digambarkan dengan persamaan garis lurus. Nilai ( $\mathrm{r}$ ) yang di tetapkan yaitu $R=1 \pm$ 0,0005 .

\section{Preparasi sampel}

Preparasi sampel merupakan proses penting yang harus dilakukan dalam penelitian dengan menyiapkan sampel sehingga sampel tersebut dapat untuk dianalisa dengan menggunakan spektrofotometri. Prosedur yang dilakukan yaitu dengan menyiapkan 
hasil sampling, lalu timbang $1 \mathrm{~g}$ sampel krim, masukan ke dalam labu ukur $20 \mathrm{ml}$ dan dilarutkan dengan metilen klorida hingga tanda batas, disonikasi selama 15 menit bertujuan untuk menghomogenkan sampel. Lalu melakukan pengenceran dengan cara pipet $4 \mathrm{ml}$ larutan sampel masukan ke dalam labu ukur $25 \mathrm{ml}$ kemudian kocok sampai homogen.

\section{Penetapan Kadar}

Prosedur yang dilakukan yaitu menimbang sampel sebanyak $1 \mathrm{~g}$ dalam labu ukur $50 \mathrm{ml}$ dan dilarutkan dengan metilen klorida sampai tanda batas, dan disonikasi selama 15 menit. Dilakukan juga pengenceran sampel dengan pipet $4 \mathrm{ml}$ larutan, dimasukan ke dalam labu ukur $25 \mathrm{ml}$ dan tambahkan metilen klorida sampai tanda batas.

Spesifikasi kadar ketoconazole yang dapat diterima berdasarkan spesifikasi produk yang ditetapkan perusahaan yaitu $90-110 \%{ }^{(19)}$. Nilai kadar tersebut diperoleh setelah melakukan blangko, dan standar. Maka muncul nilai kadar ketoconazole pada sampel dari alat pembaca instrumen spektrofotometri. Berikut ini tabel hasil penetapan kadar ketoconazole:

Tabel 6. Hasil Pemeriksaan Kadar

\begin{tabular}{|c|c|c|c|c|}
\hline \multirow{2}{*}{$\begin{array}{l}\text { Bulan } \\
\text { Penyim } \\
\text { panan }\end{array}$} & \multicolumn{2}{|c|}{ Kadar (\%) } & \multirow[b]{2}{*}{ Rata-rata $=\mathrm{SD}$} & \multirow{2}{*}{$\begin{array}{c}\text { Degradas } \\
\text { zat aktif } \\
(\%)\end{array}$} \\
\hline & $\begin{array}{c}\text { Replikasi } \\
1\end{array}$ & $\begin{array}{c}\text { Replikasi } \\
2\end{array}$ & & \\
\hline 24 & 102,99 & 101,89 & $102,44=0,78$ & - \\
\hline 30 & 101,37 & 102,80 & $102,08=1,01$ & $0,35 \%$ \\
\hline 36 & 100,54 & 101,50 & $101,02=0,68$ & $1,04 \%$ \\
\hline 42 & 99,60 & 101,25 & $100,43=1,17$ & $0,58 \%$ \\
\hline
\end{tabular}

Penentuan kadar zat aktif krim ketoconazole cukup mudah dilakukan sehingga menjadi parameter yang diamati pada pengujian stabilitas. Hasil uji nilai rata-rata konsentrasi kadar zat aktif menunjukan sediaan krim ketoconazole terjadi penurunan yaitu pada bulan ke 24 dengan nilai rata-rata $102.44 \% \pm 0,78$, pada bulan ke 30 yaitu 102,08 \% \pm 1,01 , pada bulan ke 36 dengan nilai rata-rata 101,02 $\pm 0,68$, dan pada bulan ke 42 yaitu $100,43 \% \pm 1,17$. Dari hasil penetapan kadar diatas, dapat dibuat dalam bentuk grafik untuk setiap pengujian bulan ke $24,30,36$, dan 42 sebagai berikut:

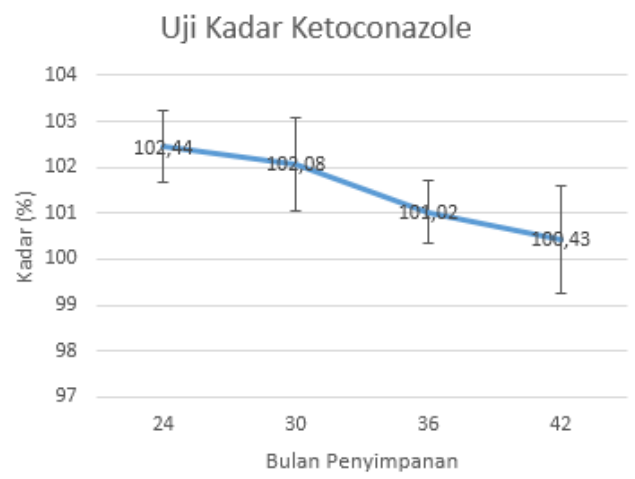

Gambar 3. Kurva hasil uji kadar 
Pada dari tabel 6 dan gambar 3 menunjukkan terjadi penurunan kadar ketoconazole selama interval waktu penyimpanan yaitu pada bulan ke 24 , ke 30 , ke 36 , hingga bulan ke 42.

\section{Pembahasan}

\section{Sampling}

Sampel krim ketoconazole yang diperoleh diambil dari sampel pertinggal secara random. Teknik sampling sebagai upaya untuk mendapatkan sampel yang representatif (mewakili), dimana teknik tersebut sudah menjadi prosedur standar di perusahaan tempat peneliti mengambil data

\section{Hasil Uji Organoleptik}

Prosedur yang digunakan untuk uji organoleptik pada sampel krim ketoconazol yaitu dilihat warnanya dengan cara sampel di pindahkan terlebih dahulu ke dalam vial bersih, lalu diamati apakah warnanya masuk spesifikasi atau tidak, karena warna memiliki peranan penting dalam penerimaan karakteristik yang paling cepat memberikan kesan. Lalu bau dilakukan dengan cara mencium langsung bau sediaan krim. Sediaan krim yang memenuhi spesifikasi akan tercium bau spesifik tanpa bau (bau lemah), sedangkan krim yang mengalami penurunan mutu akan berbau tengik.

Dari hasil pengujian terhadap warna dan bau krim ketoconazole selama waktu penyimpanan bulan $24,30,36$ dan 42 tidak menunjukan perubahan warna dan bau, hal ini dapat berarti bahwa sediaan krim tersebut stabil atau tidak terjadi reaksi kimia antara zat aktif dengan bahan tambahan. Uji homogenitas krim selama 42 bulan penyimpanan menunjukkan susunan yang homogen, selain itu krim ketoconazole juga tidak terjadi pemisahan antara fase air dan fase minyak, sehingga memenuhi standar uji kestabilan.

Ketidakstabilan krim dapat disebabkan karena reaksi kimia didalam sediaanya, yaitu terjadi perubahan kimia dari zat-zat yang bereaksi menjadi zat-zat hasil reaksi, dimana selama proses tersebut terdapat perubahan-perubahan yang dapat diamati seperti perubahan warna, pembentukan endapan, hingga terjadi perubahan suhu(13).

Ketidakstabilan krim terjadi pada penelitian Rismana $\mathrm{dkk}^{(11)}$, hasil uji pengamatan warna sediaan krim yang diuji pada suhu kamar menunjukan warna kuning muda kehijauan yang stabil hingga minggu ke-8 dan berubah menjadi coklat muda kehijauan hingga kuning coklat pada pengamatan minggu ke 10-24. Pada pengamatan bau sediaan menunjukan bau yang kuat sampai minggu ke 10, dan bau menjadi lemah pada minggu ke 16-24, hal ini diduga karena terjadi proses oksidasi selama penyimpanan.

\section{Penetapan pH}

Dari hasil uji $\mathrm{pH}$ tersebut menunjukkan stabilitas yang baik meski terjadi sedikit penurunan yaitu mencapai $\mathrm{pH} 4,2$ dibulan ke 42 , berdasarkan hasil nilai statistika yang menunjukan nilai $p>0.05$ yang berarti tidak ada perubahan yang signifikan selama penyimpanan. Secara efikasi krim dengan $\mathrm{pH}$ asam tersebut masih dapat berkerja dengan baik, menurut Luki'c et al.(2021) produk topikal termasuk krim sebaiknya 
memiliki $\mathrm{pH}$ antara 4 hingga 6 . Keasaman $\mathrm{pH}$ pada kulit diketahui sebagai faktor yang mengatur dalam pemeliharaan homeostasis korneum dan permeabilitas barier kulit(25).

Pada pengujian $\mathrm{pH}$ sediaan krim masih bersifat aman karena masih berada dibawah $\mathrm{pH}$ netral sehingga tidak terlalu bersifat basa, dan tidak menyebabkan iritasi jika diaplikasikan pada kulit. Menurut Gozali et a/(14), nilai $\mathrm{pH}$ terlalu asam dapat menyebabkan kulit gatal-gatal dan bersisik, dan nilai $\mathrm{pH}$ melampaui 7 dikhawatirkan dapat menyebabkan iritasi kulit

Kami menemukan penelitian pengembangan formulasi ketoconazole dalam bentuk semi solid dan liquid telah dilakukan pengkajian stabilitas dimana pada $\mathrm{pH} 7$ masih dapat mempertahankan kestabilannya hingga 15 bulan(20). Spesifikasi nilai $\mathrm{pH}$ untuk sediaan krim disampaikan oleh Tranggono dan Latifah ${ }^{(15)}$ bahwa nilai $\mathrm{pH}$ untuk sediaan topikal harus disesuaikan dengan $\mathrm{pH}$ kulit. Pengujian $\mathrm{pH}$ dilakukan dengan menggunakan $\mathrm{pH}$ meter. Kestabilan $\mathrm{pH}$ merupakan salah satu parameter penting yang menentukan stabil atau tidaknya suatu sediaan. Pengujian $\mathrm{pH}$ sediaan bertujuan untuk mengetahui keamanan sediaan saat digunakan agar tidak mengiritasi kulit. Dengan mengetahui profil perubahan $\mathrm{pH}$ sediaan dapat memberikan gambaran tentang stabilitas sediaan tersebut.

\section{Uji Viskositas}

Penurunan viskositas krim selama interval waktu penyimpanan. dapat dipengaruhi karena perubahan fisika dan kimia selama penyimpanan disebabkan karena meningkatnya jumlah air pada tiap formula dan menurunnya jumlah emulsifier dalam sediaan. Berdasarkan penelitian yang telah dilakukan oleh Sulistyaningsih et al.(22) dalam pengkajian stabilitas sediaan emulgel ketoconazole pada parameter viskositas setelah penyimpanan 35 hari ditemukan bahwa viskositas mengalami sedikit perubahan, namun perubahan viskositas ini masih mempertahankan kestabilannya

Pada analisis perbedaan viskositas dari waktu penyimpanan menggunakan uji one-way ANOVA, berdasarkan hasil nilai statistika bahwa didapat nilai $p>0.05$ yang berarti tidak ada perubahan viskositas yang signifikan selama penyimpanan. Nilai viskositas yang baik dari sediaan farmasi yaitu memiliki nilai yang tinggi, dimana semakin tinggi viskositas maka pergerakan partikel akan semakin sulit sehingga bahan akan semakin stabil(16,17). Hasil penelitian ini menunjukkan bahwa nilai viskositas sediaan krim masih memenuhi syarat sediaan krim SNI 16-4399-1996 yaitu pada kisaran $2.000-50.000$ $\mathrm{cp}^{(26)}$.

\section{Uji Kadar Ketoconazole}

Penurunan kadar ketoconazole terjadi selama interval waktu penyimpanan yaitu pada bulan ke 24, ke 30, ke 36, hingga bulan ke 42. Degradasi zat aktif ditentukan dalam bentuk persentase dimana dibulan ke 30 terjadi penurunan kadar ketoconazole sebesar $0,35 \%$, dibulan ke 36 sebesar $1,04 \%$, dan di bulan ke 42 terjadi penurunan sebesar $0,58 \%$. Meski terjadi penurunan kadar, sampel tetap memiliki stabilitas yang baik selama penyimpanan dilihat dari penurunan kadar zat aktif kurang dari $5 \%$ dan nilai statistika yang menunjukan nilai $p>0.05$ yang berarti tidak menunjukan degradasi yang 
memiliki $\mathrm{pH}$ antara 4 hingga 6 . Keasaman $\mathrm{pH}$ pada kulit diketahui sebagai faktor yang mengatur dalam pemeliharaan homeostasis korneum dan permeabilitas barier kulit(25).

signifikan. Pada pengujian ini sediaan krim masih bersifat aman karena masih berada di rentang $90-110 \%$. Nilai ini berasal dari standar yang berlaku di farmakope bahwa untuk analisia zat aktif dalam obat disyaratkan kadarnya berkisar $90-110 \%(19)$. Apabila di dalam obat di batas bawah spesifikasi (BBS) kurang dari $90 \%$ bahan aktif maka obat tersebut tidak memiliki kemampuan efikasi. Sebaliknya jika nilai batas akhir spesifikasi (BAS) yang lebih dari $110 \%$ bahan aktif akan mengakibatkan over dosis terhadap penggunaannya.

Dalam penelitian yang dilaksanakan Allen dan Erickson(21) mengenai uji stabilitas dengan parameter kadar ketoconazole dalam sediaan liquid selama interval penyimpanan, menunjukkan sediaan ketoconazole $20 \mathrm{mg} / \mathrm{mL}$ liquid tetap mempertahankan penampilan, $\mathrm{pH}$ dan juga masih mempertahankan kadar ketoconazole setelah penyimpanan selama 60 hari pada kondisi $25^{\circ} \mathrm{C}$.

Penentuan ketelitian juga dilakukan untuk melihat sejauh mana ketelitian metode analisa dalam penentuan kadar. Penetapan dilakukan dengan melihat besarnya data Standar Deviasi (SD) dari penetapan kadar tiap interval waktu penyimpanan. Semakin kecil nilai SD yang didapatkan maka semakin besar ketelitian metode analisa yang digunakan. Hasil penelitian ini, menyatakan bahwa SD yang dihasilkan yaitu pada bulan ke $240,78 \%$, bulan ke 30 yaitu 1,01\%, bulan ke $360,68 \%$ dan bulan ke 40 yaitu 1,17\%. Nilai ini menyatakan bahwa ketelitian metode analisis bisa dipercaya karena telah memenuhi persyaratan, yaitu kurang dari $2 \%$.

Pada penelitian Fitriyani(18) menunjukkan bahwa uji validasi metode penetapan kadar ketoconazole menggunakan kromatografi cair kinerja tinggi dan aplikasinya dalam sediaan krim memenuhi persyaratan sebagai berikut: Uji presisi dengan nilai SD 0,237\%, uji akurasi 99,806\% - 100,020\%, selektivitas yang baik, linieritas dengan nilai korelasi ( $r$ ) 0,99986, dengan batas deteksi (LOD) sebesar $0,196 \mu \mathrm{g} / \mathrm{mL}$ dan batas kuantifikasi (LOQ) sebesar 0,652 $\mu \mathrm{g} / \mathrm{mL}$. Hasil penetapan kadar menggunakan metode KCKT pada sediaan krim diperoleh hasil 100,101\%..

\section{Kesimpulan}

Berdasarkan hasil penelitian diatas maka dapat disimpulkan bahwa data yang diperoleh dari uji stabilitas jangka panjang sediaan krim ketoconazole ditinjau dari pengujian organoleptik, $\mathrm{pH}$, viskositas, kadar zat aktif menunjukkan bahwa sediaan krim ketoconazole tetap stabil selama 42 bulan penyimpanan.

\section{Daftar Pustaka}

1. Ansel HC. Pengantar bentuk sediaan farmasi. Edisi IV. Jakarta UI Press; 2008

2. Pramudita N. Uji stabilitas fisik dari ampas kelapa menggunakan emulgator anionik dan nonanionik, (Skripsi). Makasar: UIN Alauddin; 2016 
3. Dewi RE, dan Anwar. Uji stabilitas formulasi yang mengandung ekstrak kacang kedelai (Skripsi). Depok: Fakultas Farmasi Universitas Indonesia; 2016.

4. Anief M. 2010. Ilmu Meracik Obat. Cetakan ke-15. Gadjah Mada Press. Yogyakarta

5. BPOM. Pedoman Cara Pembuatan Obat yang Baik (CPOB). Jakarta: Badan Pengawas Obat dan Makanan; 2018

6. European Medicines Agency. ICH Topic Q 1 A (R2) Stability Testing of new Drug Substances and Products, London; 2006.

7. Wardani PM. Uji stabilitas fisika dan kimia sediaan sirup rekonstitusi yang mengandung tiamfenikol (skripsi). Purwokerto: Universitas Muhammadiyah Purwokerto; 2016.

8. Oktaviasari L, Zulkarnain AK. Formulasi dan Uji Stabilitas Fisik Sediaan Lotion O/W Pati Kentang (Solanum Tuberosum L.) Serta Aktivitasnya Sebagai Tabir Surya. Majalah Farmaseutik. 2017; Vol. 13 (1) : 9 - 27

9. Hamsinah, S. Darijanto, R. Mauludin. Uji stabilitas formularium krim tabir surya serbuk rumput laut (skripsi).Bandung: Institut Teknologi Bandung; 2016.

10. Maulina DI. Uji stabilitas fisik dan aktifitas antioksidan sediaan krim yang mengandung ekstrak umbi wortel (Skripsi). Depok: Fakultas Farmasi Universitas Indonesia: 2011

11. Rismana E. Susi K, Idah R, Nizar, Erna Y. Pengujian stabilitas sediaan antiacne berbahan baku aktif kitosan ekstrak manggis, Bul. Penelit. Kesehat. 2013; Vol. 41, No. 4, $207-216$

12. Fraihat S.M., dan Bahgat K.M., Spectrophotometric Methods for the Determination of Ketoconazole in Pharmaceutical Dosage Forms. Tropical Journal of Pharmaceutical Research. 2014; vol 13 (9).

13. Pudjaatmaka dan A Hadyana. Kamus Kimia. Jakarta: Balai Pustaka; 2002.

14. Gozali D, M Abdassah, A Subghan, SA Lathiefah. Formulasi krim pelembab wajah yang mengandung tabir surya nanopartikel zink oksida salut silikon, Jurnal Farmaka; 2009; Vol 7 (1), 37-47.

15. Tranggono RI, Latifah F. Buku pedoman ilmu pengetahuan kosmetik, Jakarta: Penerbit Gramedia Pustaka Utama; 2007.

16. Schmitt WH, Skin care products. In: Williams, D.F. and W.H. Schmitt (Ed). 1996. Cosmetics and Toiletries Industry 2nd Ed. London: Blackie Academic and Profesional; 1996

17. Erwiyani AS, D Destianti, SA Kabelen. Pengaruh lama penyimpanan terhadap sediaan fisik krim daun alpukat (Persen americana Mill) dan daun sirih (Piper bettle Linn). Indonesian Journal of Pharmacy and Naturnal Product. 2018; Vol 1 (1) : 26-27. 
18. Fitriyani E. Validasi Metode Penetapan Kadar Ketokonazol Menggunakan Kromatografi Cair Kinerja Tinggi dan Aplikasinya dalam Sediaan Krim. [diunduh 12 Agustus 2021]. Tersedia dari: http://ejournal.unsrat.ac.id.

19. Departemen Kesehatan RI. Farmakope Indonesia. Edisi IV, Jakarta: Departemen Kesehatan RI; 1995.

20. Skiba M., M Skiba-Lahiani, H Marchais, R Duclos, P Arnaud. Stability assessment of ketoconazole in aqueous formulations, International Journal of Pharmaceutics; 2000; Vol 198(1):1-6

21. Allen LV, MA Erickson. Stability of ketoconazole, metolazone, metronidazole, procainamide hydrochloride, and spironolactone in extemporaneously compounded oral liquids, Am J Health Syst Pharm. 1996; 1;53(17):2073-8

22. Sulistyaningsih, Gozali D, Rd. M Bambang, Mustarichie R. Ketoconazole Emulgel Formula Activity Test against Microsporum gypseum and Candida albicans, J. Pharm. Sci. \& Res. 2017; Vol. 9 (12) 2458-2462

23. Rawlins EA. Bentleys of Pharmaceutics. Edisi Kedelapanbelas. Baillierre Tindal. London. 2003

24. Erwiyani AR, Luhurningtyas FP, Sunnah I. Optimasi Formula Sediaan Krim Ekstrak Etanol Daun Alpukat (Persea Americana Mill) dan Daun Sirih Hijau (Piper Betle Linn). Cendekia J Pharm. 2017;1(1).

25. Luki'c M. Panteli'c I. Savi'c SD. Towards Optimal pH of the Skin and Topical Formulations: From the Current State of the Art to Tailored Products. Cosmetics 2021, 869

26. Badan Standarisasi Nasional. Sediaan Tabir Surya SNI 2016-4399-1996. Standar Nasional Indonesia, Jakarta. 1996

27. Rao, Purushotham K, Khaliq K, Sambhaji K, Patil SK, Sagare P. Design Of Ketoconazole Vanishing Cream For The Treatment Of Scalp Diseases.Advances in Pharmacology and Toxicology; Jalgaon Vol. 11, Iss. 1, (Apr 2010): 137-144. 